Introduction The use of electronic devices (smartphones, tablets, laptops etc.) amongst the younger generation in particular has exploded in recent years. Studies estimate $92 \%$ of teenagers go online daily and $24 \%$ describe themselves as constantly connected. Their habits, the addictive nature of technology, the advice they receive and equipment/furniture they're provided often means they use this technology for long periods in awkward postures. What effect musculoskeletal and psychosocial effects is this having during developmental stages that may then affect these generations for the rest of their lives?

Methods With the negative effects of technology use being cumulative, taking a long time to develop into diagnosable conditions, we aim to continue this research over a number of years. For the first round we will select students from Primary and Secondary education with the aim of revisiting our sample group every three years (harmonising with future ICOH Congresses) to re-evaluate their health and wellbeing in that instant and over time. At each interval the study will include a physical examination and a questionnaire on technology usage habits, general physical and psychosocial health and any symptoms attributable to technology use.

Result We will present the results of the first year study at ICOH2018 so this is currently a hypothesis. We believe that compared with previous generations the increasing habitual widespread use of technology during childhood may have a significant detrimental impact on future MSD's, employee productivity and absenteeism rates.

Discussion Based on our hypothesis we believe this will create a need to establish new ergonomic working methods and develop new equipment and furniture to help mitigate the effects of this behaviour. This will fall into two areas; preventative measures for children at home and in the classroom and remedial actions for employers inheriting the conditions their new employees bring into the workplace.

\section{8b DIS 45001, HEALTH AND SAFETY IN THE MAKING (DEVELOPING INTERNATIONAL HEALTH AND SAFETY STANDARDS)}

Sally Swingewood*. Lead Programme Manager, Governance and Resilience Sector British Standards Institution $\mathrm{Br}$

\subsection{6/oemed-2018-ICOHabstracts.44}

Introduction It took over 30 years to gain enough support to produce a truly global $\mathrm{OH}$ and $\mathrm{S}$ management system standard, despite conservative estimates of 250 million occupational accidents and 160 million occupational diseases each year worldwide over a million work-related fatalities every year. It took four years of work involving experts from 63 countries and 9 international organisations (including the International Labour Organisation and the International Trades Union Congress) to produce a draft $88 \%$ of those involved can support. Methods The standard has been developed through a consensus-based process including 10 physical meetings (involving up to 100 people in countries spanning four continents), electronic meetings and teleconferences. Each formal iteration of the standard has been balloted, with a minimum of $75 \%$ approval needed to progress to the next stage and every comment submitted on each draft considered.

Result The standard is likely to publish at the end of 2017 or early in 2018 and is intended to replace the current widely used OHSAS 18001 standard, which was developed by a smaller number of countries before an agreement was made for a full ISO (International Organisation of Standardisation) Discussion To what extent can standardisation help improve $\mathrm{OH}$ and $S$ performance across the world? What are the barriers to use and limitations? How can we promote proactive $\mathrm{OH}$ and $\mathrm{S}$ management, particularly in relation to health and wellbeing?

\section{C AEROTOXIC SYNDROME: A NEW OCCUPATIONAL DISEASE? (ADVERSE HEALTH EFFECTS EXPERIENCED BY AIRCREW EXPOSED TO AIRCRAFT CONTAMINATED AIR)}

Susan Michaelis. University of Stirling, UK

10.1136/oemed-2018-ICOHabstracts. 45

Introduction Since the 1950s pressurised aircraft cabin air has been drawn unfiltered from turbine jet engines as 'bleed air'. Therefore emissions from engine oil seals leads to contamination of the breathable cabin air. The synthetic oils include a wide range of hazardous substances including the organophosphates, and a complex pyrolysed mixture. Oil seals are reported to produce a noticeable cabin fume event in $1 \%$ of flights. ${ }^{1}$ However, to function oil seals 'weep' lubricant at varying stages of normal engine operation, ${ }^{2}$ so there is always low level air contamination which crew and frequent flyers are cumulatively exposed to for $100 \mathrm{~s}$ of hours annually. Reports of adverse effects specifically related to the aircraft environment have continued since the early 1950s. ${ }^{3,4}$ Short and long-term effects, termed 'Aerotoxic Syndrome', primarily involve irritant, sensitising, neurological, neuropsychological, respiratory, cardiovascular and other general effects. ${ }^{4}$

Methods A review of the various actions undertaken by the aviation manufacturer's, airlines regulators, governments and independent studies will be outlined. A selection of incident and accident reports and bureau of air safety recommendations will be highlighted. The implications for both aircrew, frequent flyers and susceptible individuals will be discussed.

Result The aviation industry has inadequately addressed this long-standing problem, despite it being a clear threat to flight safety, occupational health and safety, occupational and public health. There is a need for further research to be undertaken to help address this important problem relevant to anyone who flies in aircraft as crew or as a passenger.

Discussion In view of the need to prevent incidents and accidents related to aircraft contaminated air supplies and the subsequent occupational and public health issues, there is a clear need for action to be taken to assess the scale of the problem and highlight the need for preventative actions.

\section{SPECIAL SESSION ON TRAFFIC MEDICINE - AM I SAFE TO DRIVE?}

Declan Whelan. Occupational Health Unit CIE, Dublin, Ireland

\subsection{6/oemed-2018-ICOHabstracts.46}

Aim Explore Medical aspects of Fitness to drive and Safety implications

${ }^{1}$ Dr Donna Morgans, ${ }^{2}$ Dr Oern Foss, ${ }^{3}$ Professor Desmond O’Neill

${ }^{1}$ London for Transport, London, England

${ }^{2}$ Norwegian State Railway, Oslo, Norway

${ }^{3}$ National office for Traffic Medicine, Dublin, Ireland 